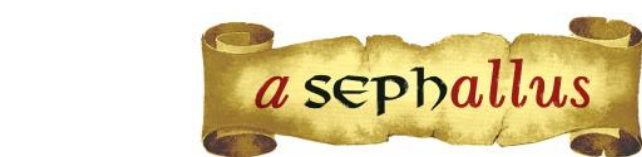

Revista aSEPHallus de Orientação Lacaniana

Núcleo Sephora de Pesquisa sobre o Moderno e o Contemporâneo ISSN 1809 - 709 X

\title{
Orientação do real
}

\author{
Erly Alexandrino da Silva Neto \\ Psicólogo / Universidade Federal do Espírito Santo (Espírito Santo, Brasil) \\ Especialista em Psicanálise/EAP/FAFIA \\ Mestre em Teoria Psicanalítica pelo Programa de Pós-graduação em Teoria Psicanalítica / \\ Universidade Federal do Rio de Janeiro (Rio de Janeiro, Brasil) \\ E-mail: erlyneto@gmail.com
}

\begin{abstract}
Resumo
A clínica psicanalítica no século XXI apresenta configurações distintas da clínica de Freud: outro laço social, outras subjetividades e novas discussões diagnósticas. Uma excelente referência teórica nesta problemática são os cursos de orientação lacaniana, ministrados por Jacques-Allain Miller. Em um deles, Miller afirma que é possível encontrar no último ensino de Lacan subsídios para concluir que o analista é o proton pseudos da psicanálise. Neste artigo, o autor efetua a leitura dos últimos seminários de Lacan (em especial O sinthoma) e não encontra nenhuma fórmula que, fora de contexto, pudesse garantir inequivocamente esta assertiva. Diferentemente da orientação para o real proposta por Miller, foi encontrada a orientação do real. Esta diferença motivou um trabalho de pesquisa que acompanhou o estatuto do analista em Freud e em Lacan e construiu este percurso até as últimas formulações lacanianas.
\end{abstract}

Palavras-chave: clínica, lugar do analista, sinthoma, orientação do real.

\section{Orientation du réel}

La clinique pscyhanalytique du XXIe siècle présente des configurations distinctes de celle de Freud: un autre lien social, d'autres subjectivités, et de nouvelles discussions diagnostiques. Les cours d' orientation lacanienne enseignés par Jacques-Alain Miller, sont une excellente référence théorique dans cette problématique. Au cours de l'un d'eux, Miller affirme qu'il est possible de trouver dans le dernier enseignement de Lacan des elements suffisants pour conclure que l'analyste est le proton pseudos de la psychanalyse. Dans cet écrit, l'auteur fait la lecture des derniers Séminaires de Lacan, (Le sinthome en particulier) et ne trouve aucune formule qui puisse, séparée de son contexte, prouver irréfutablement cette affirmation. De manière différente de l'orientation pour le rée/ propose par Miller, l'auteur propose l'orientation du reel. Cette difference a motivé un travail de recherché qui accompagne le statut de l'analyste chez Freud et Lacan et construit ce parcours jusqu'aux dernières formulations lacaniennes.

Mots-clés: clinique, place de l'analyste, sinthoma, orientation du reel.

\section{Real's orientation}

The psychoanalytic clinic in the XXI century has distinct clinical settings from Freud's creation: another social bond, other subjectivities and new diagnostic discussions. Excellent theoretical references in this issue are the Lacan orientated courses, taught by Jacques-Allain Miller. In one of them, Miller states that it is possible to find subsidies in the last teaching of Lacan to conclude that the analyst is the proton pseudos of psychoanalysis. In this article, the author makes the reading of Lacan's final Seminars (especially Le synthome) and finds no formula that, out of context, could unequivocally guarantee this statement. Unlike the orientation for the real proposed by Miller, the author of this paper creates the orientation of the real. This difference led to a research that follows the analyst's status in Freud and Lacan and builds this route until the final statements of Jacques Lacan.

Keywords: clinical, place of the analyst, synthome, orientation of the real. 


\section{Orientação do real ${ }^{1}$}

\section{Erly Alexandrino da Silva Neto}

\section{Como se analisa hoje em dia?}

A psicanálise de orientação lacaniana, tal como é chamada a ministrada pelos cursos da Association Mondiale de Psychanalyse (AMP), tem sido construída em torno de uma linha que é chamada "orientação para o real". Os últimos cursos de Jacques-Allain Miller (2007, 2008, 2009, 2011) não só adotam esta direção de maneira manifesta, como definem o que ela é.

Para construir o assoalho teórico desta orientação, Miller (2007, 2008, 2009, 2011) se dedica a, fundamentalmente, duas coisas: escandir o ensino de Lacan em três momentos e demonstrar a hipótese de que no último ensino de Lacan, o terceiro, há a construção de um estatuto para o real que difere dos ensinos anteriores.

Este terceiro ensino, segundo o próprio Miller, tem sua porta de entrada no Seminário 19 (Lacan, 1971-1972) - "Aqui começa o último ensino de Lacan. (. . .) Ali está tudo o que ele ensinou, e no entanto, é tudo novo, renovado, virado de pernas pro ar", escreve ele na contracapa -, e é firmemente alicerçado nos Seminários 20 (Lacan, 1972-1973) e 23 (Lacan, 1975-1976).

A partir destas coordenadas, Miller constrói uma teoria que propõe um inconsciente real (2007), a interpretação borromeana (2011) e a hipótese de que todo mundo delira (2007), ou seja, da foraclusão generalizada do Nome-do-Pai na contemporaneidade, para repaginar a clínica.

A linha de desenvolvimento teórico a respeito da clínica psicanalítica contemporânea que a AMP vem desenvolvendo sobre os novos sintomas e as psicoses ordinárias faz eco nas dificuldades que a experiência me mostrou: dificuldade para realizar certos diagnósticos, para intervir a partir da interpretação e para manejar certas transferências inusitadas. Alguns candidatos à análise que recebi me fizeram considerar a tentadora proposta de categorizá-los como limítrofes (Bergeret, 1998), mas essa solução diagnóstica não resolve em nada o problema que tenho à minha frente, que é o de saber conduzir uma análise sob estas condições. Afinal, um limítrofe é um psicótico? É um neurótico? Um perverso? Pode ser tratado como um deles? Aliás, cabe saber, ele pode ser tratado? Se sim, como?

Visto que os trabalhos de construção da categoria diagnóstica 'limítrofe' não vão muito além das descrições fenomenológicas - apesar dos esforços de Bergeret (1998) para dar sua dinâmica e estrutura -, eles não se mostraram interessantes, no meu caso, para a construção de uma prática clínica pautada pela psicanálise. Os cursos de Miller, ao contrário, parecem estar atinados para essa inserção da clínica psicanalítica no mundo atual, propondo, não uma nova nosografia, mas uma problematização da orientação e da estrutura da própria teoria psicanalítica, bem como a deteç̧ão de um certo modo de adoecer característico da época. Olhemos essa proposta mais de perto. 
Miller (2011) propõe, na construção teórica da orientação para o Real, a cisão do inconsciente entre inconsciente transferencial e inconsciente real. $\mathrm{O}$ primeiro, um inconsciente relacional, possível devido à própria psicanálise, criado por ela, um inconsciente que é saber, história, que é Outro, ou seja, o inconsciente lacaniano clássico (Lacan, 1955-1956, 1957-1958, 1953, 1957, 1958, dentre outros); o segundo, um inconsciente sozinho, que não faz laço, que demonstra que a articulação entre o significante e o saber $\left(S_{1}-S_{2}\right)$ é "precária" (Miller, 2009) e que a linguagem é não mais do que aparelho de gozo de lalíngua, trazendo a profunda irredutibilidade de um gozo que não se deixa comunicar, que é da ordem do para si sozinho (Miller, 2009 e 2010).

O inconsciente como real é proposto para abarcar aquilo que supunha não 'fazer transferência', tais como as psicoses, o autismo e o gozo autoerótico do excesso ou de fenômenos resistentes às intervenções do analista, como a urgência pulsional (atualidade e agudeza do sofrimento), a fixidez/adesividade da libido (Freud, 1937) e os traços de caráter (Coelho dos Santos, 2014).

Desta proposta de cisão do inconsciente, no âmbito da teoria, Miller (2011) extrai algumas consequências para o campo da técnica, uma elucubração de como fazer com que esta nova concepção de inconsciente apareça na técnica interpretativa, porque, segundo ele, uma teoria da psicanálise se julga conforme as consequências que ela tira, relativas à interpretação.

Assim, o autor passa a buscar o que seria uma interpretação 'borromeana', baseada na teoria dos nós em Lacan, enfatizando que, para tanto, precisamos considerar o sinthoma na interpretação, valendo-nos do efeito de furo que o simbólico faz no real, apoiado na asserção lacaniana de que "temos apenas o equívoco como arma contra o sinthoma" (Lacan, 1975-1976, p. 18). Isso quer dizer que, ao jogar com as palavras, pode-se excluir o sentido cristalizado delas que é o que dá consistência à fantasia - e promover um não-sentido que faz graça, faz furo, revelando o arbitrário da construção que, antes, parecia inexorável. Miller (2011) chama essa técnica de manipulação interpretativa.

É bem verdade que não há nada de novo nisso. Desde o seminário As formações do inconsciente (Lacan, 1957-1958), já havia a proposta da interpretação como pas du sense (simultaneamente lido como passo de sentido e sem sentido), que é a forma de retirar as palavras do sentido habitual e criar um sentido novo. Também é muito semelhante à função do corte que destaca o objeto a na fantasia e revela o sujeito como desejante (Lacan, 1962-1963, 1964), e mesmo a orientação de Lacan no seminário O sinthoma (1975-1976) não me parece ir muito além desses dois passos, acrescentando, entretanto, que há que se preservar a função do real enquanto "um caroço em torno do qual o pensamento divaga, mas seu estigma, o do real como tal, consiste em não se ligar a nada" (Lacan, 1975-1976, p. 119). Isso equivale dizer, precisamente, que à altura do seminário $O$ sinthoma, o axioma não é nem o sujeito do significante - com seu parceiromáquina (Miller, 1998, Silva Neto, 2011), nem o fantasma unissex ( $\$<>$ ), mas a não-relação sexual (Coelho dos Santos, 2014). Ou seja, a interpretação que visa o sinthoma, o real do sintoma, 
é aquela que pode mostrar que o que quer que esteja articulado em palavras - o sintoma, a fantasia, os sonhos, os chistes e todas as formações do inconsciente -, isso não é o real; o real se trata, justamente, do não há relação sexual, portanto, os engates são contingenciais. Entretanto, não é a troco de uma inacessibilidade trágica que Lacan formula essas coisas, mas para dizer que as formações do inconsciente não são mais do que bobagens de um inconsciente brincalhão e gozador, desmontáveis, passíveis do jocoso e que, sim, articulam algo de real, mas isso é só um modo de gozar. Não precisa ser tão sofrido.

O primeiro e o segundo aspectos da orientação lacaniana de Miller - o inconsciente real e a interpretação borromeana - podem ser sucintamente apresentados desta maneira, e parecem estar em bom acordo com as elaborações lacanianas. Entretanto, encontro um problema nesta orientação quando procuro extrair as consequências de sua teoria para a estruturação da clínica e do lugar do analista.

Quanto à clínica, o que se passa é uma mudança de concepção. Em Freud (1910, 1911, 1923, 1924a, 1924b, 1937, 1940, entre outros) há um esforço para estruturar a experiência psicanalítica em uma clínica de diferenças qualitativas entre o analisável e o não analisável, o neurótico e o psicótico, o terminável e o interminável, o consciente e o inconsciente, fatores constitucionais (fisiológicos) e históricos etc. Há uma diferença estrutural entre uma coisa e outra, e essa diferença deve ser determinada pelo psicanalista para que ele possa construir que tipo de intervenções fará a cada caso, inclusive para saber se não há nada que possa ser feito, pois Freud não recomendava a psicanálise para as psicoses ou para fortes fatores constitucionais. É claro em seu trabalho que, apesar de a psicanálise lançar luz sobre os fenômenos da psicose, não se deve oferecer aos psicóticos sua terapêutica, sob pena de empreender esforços vãos, na melhor das hipóteses, acarretando descrédito para ela (a psicanálise) e desapontamentos graves para o paciente.

Já em Lacan, observamos a manutenção desta estruturação da clínica durante o percurso de seu primeiro e segundo ensinos, percurso este que pude traçar na dissertação que originou este artigo (Silva Neto, 2013). Se há inscrição do Nome-do-Pai, há Édipo e, portanto, trata-se de uma neurose; caso o sujeito passe ao largo da metáfora paterna, há foraclusão do Nome-do-Pai e, portanto, há psicose. Isso tudo pressupõe uma estrutura subjetiva de autonomia do significante em relação a uma heteronomia do significado. Não há necessidade de reconstruir aqui o que cada termo desses significa, para isso reporto o leitor aos trabalhos de Lacan (1955-1956, 1957-1958, $1953,1957,1958)$ ou à minha dissertação, isso para não citar inúmeros outros. O realmente crucial aqui é compreender que a experiência psicanalítica, tanto em Freud quanto em Lacan, sempre foi estruturada em uma clínica de saltos qualitativos entre esta ou aquela estrutura subjetiva, esta ou aquela instância do psiquismo, este ou aquele tipo de fixação.

No período do terceiro ensino de Lacan, entretanto, a leitura feita por Miller e por vários outros autores é a de que a clínica passa a ser continuísta, ou seja, não é mais um salto qualitativo 
entre as estruturas subjetivas ou clínicas que estarão em pauta, mas a diferença quantitativa na pulsão e na invasão do gozo (Coelho dos Santos, 2014). Isso realmente pode ser constatado quando Lacan (1973-1974, 1975-1976) passa da primazia do simbólico à equivalência entre os registros do Real, Simbólico e Imaginário.

O problema que se colocou para mim diante desta perspectiva, entretanto, não se trata apenas da mudança de perspectiva entre uma clínica descontinuísta, estrutural, para uma clínica continuísta, dos quantitativos, mas de uma consequência específica para o lugar do psicanalista que a leitura de Miller, em exclusividade, provocou em mim. É preciso discorrer com mais detalhes.

\section{Clínica, discurso do capitalista e sujeitos contemporâneos: não tão desabonados do inconsciente assim}

O problema da clínica é algo que se coloca com mais de complexidade porque é preciso delinear a situação do laço social em nossa época, uma vez que ele nos coloca problemas específicos e a concepção continuísta é uma resposta ao problema clínico que as subjetividades de nossa época apresentam. A forma que a psicanálise lacaniana dá a esse laço, utilizando-se das fórmulas dos discursos do Seminário O avesso da psicanálise (Lacan, 1969-1970), e em sua elaboração posterior no escrito "Televisão" (Lacan, 1973), é a do discurso do capitalista. A problemática típica desta forma de laço social é a das relações com os objetos de gozo, que "constrói apenas um único laço, bem pouco social, entre o indivíduo e os produtos" (Soler, 2012, p. 208).

Esse laço, Lacan (1968-1969) apontou, é a função de captação do mais-de-gozar que os gadgets produzidos nos proporcionam. Eles fazem função de objeto, mas destacados de um outro a quem o sujeito possa se endereçar. São as mamadeiras, os arquivos de música, as fotos e vídeos eróticos e, enfim, tudo isso resultando em muito dejeto (objeto anal).

Ao promover o consumo dos objetos descartáveis como tática de mercado, o que é realizado é uma insatisfação estratégica da demanda para que ela se renove cada vez com mais vigor. O discurso do capitalista, nesse sentido, promove no discurso "a multiplicação das vítimas, com a escalada correlativa da ideologia da vitimização", onde "o um por um tornou-se regra, e assistimos a fenômenos de fala sem precedentes" (Soler, 2012, pp. 209-210).

Estes fenômenos de fala são as profusões de relatos que pululam nas mídias eletrônicas e nas pesquisas de opinião, tendo a função de expor o gozo ou de servirem ao gozo. Isso não vai ao encontro da análise, "pois gerir o gozo e interrogá-lo são duas operações bem distintas" (Soler, 2012, p. 214). Para que se possa interrogá-lo, é preciso que a fala não se resuma à dimensão da catarse, da opinião ou do gozo, mas que alcance a dimensão da verdade. Isso equivale a dizer que a relação do sujeito com o Outro a quem interroga sobre o desejo é apagada, como consequência, 
há a desresponsabilização de cada sujeito sobre sua condição de desejante, precariedade de fala, debilidade mental.

A exposição do gozo próprio como algo precioso e compartilhável é justamente o que Coelho dos Santos (2014) aponta como o desejo de ser ator. Segundo a autora, a subjetividade de nossa época não sofre de seus sintomas da mesma maneira que os sujeitos vitorianos sofriam. Àquela altura, a forma típica de adoecimento neurótico contava com uma forte relação ao Outro (diferentemente do laço típico no discurso do capitalista), de modo que a principal fonte de malestar era o retorno do recalcado sob a forma de sintomas como mensagens cifradas ao Outro. $\mathrm{Na}$ atualidade, entretanto, os sujeitos sofrem menos do retorno do recalcado do que dos excessos pulsionais, da invasão de gozo, que advém da elevação do sintoma à dignidade da Coisa (Coelho dos Santos, 2014).

Desta forma, os sujeitos chegam ao consultório do analista queixando-se de adições, pânico, depressão e toda a sorte de afecções narcísicas oriundas da elevação de traços de seu caráter à condição de sublimes, como o escabelo lacaniano de Joyce (Lacan, 2003): o pequeno pedestal onde ele se coloca ao escrever seu nome próprio como autor, como aquele que ocuparia os acadêmicos por trezentos anos.

Se, entretanto, por um lado os pacientes que recebemos em nossos consultórios estão marcados pelo amor aos próprios traços de caráter, pelo gosto exagerado por suas próprias idiossincrasias, por outro, não apresentam nenhum traço da solidão assumida de Joyce, que recusa a oferta de uma psicanálise com Jung. Os sujeitos que nos procuram queixam-se de algum malestar difuso oriundo, por vezes, do próprio gozo ou traço de caráter que vangloriam, exigindo uma cura compacta, consumível, que os livre do sofrimento e os habilite a dar continuidade à sua preciosa maneira de gozar. Bem mais débeis do que o exemplo de Joyce, relutam se engajar na dimensão da verdade, na dimensão moral, que é a dimensão própria à análise, e precisam ser trazidos até ela.

Para escutar estes sujeitos, é preciso saber em que lugar eles nos solicitam, que tipo de transferência estabelecem e que tipo de intervenção tem eficácia. Quando há forte relação ao Outro, engajamento na dimensão da verdade, é fácil detectar estes elementos, pois a estrutura é evidente, mas quando a fala é débil e o gozo está no centro, como saber se o caso é uma psicose ou neurose? E finalmente posso apontar o problema quanto à clínica na orientação lacaniana de Miller: o que ocorre é que, com a tese de que todo mundo delira (2007), o que é promovido é o apagamento da diferença clínica entre neurose e psicose, entregando o psicanalista ao papel, estranho, de fazer ecoar os significantes autoeróticos do ser falante (Miller, 2011).

A meu ver, essa não é uma boa saída, pois uma relação débil ao Outro requer ainda mais perícia e habilidade para ser lida. Neste contexto, vejo que uma conceituação sólida do lugar do analista é crucial, especialmente pelo caráter de 'pressa' e demanda de eficácia que estes casos impõem às primeiras intervenções, de modo que as transferências possam se estabelecer antes do 
pior, ou seja, para quem goza do objeto contornando o Outro, é preciso se colocar à frente deles neste lugar. $\mathrm{O}$ que Miller propõe, entretanto, é diverso disso, o que me leva a comentar sobre o segundo problema, o do lugar e do estatuto do analista nos cursos de orientação lacaniana de Miller.

\section{Analista como proton pseudos diante do gozo}

Miller levanta questões sobre o papel do analista diante do inconsciente real e do Gozo com G maiúsculo, pois este inconsciente seria aquele que não permite nenhuma amizade, que é autístico, destinado ao Um-corpo e não ao Outro (Miller, 2009), chegando a dizer que o psicanalista, diante disso, é o proton pseudos da psicanálise, devido à "inserção de um outro sujeito na relação que se mantém com o inconsciente real" (Miller, 2010, p. 19).

Para mim isso assume dois sentidos muito problemáticos. 0 primeiro é o de que 0 psicanalista é uma mentirinha, invenção louca de um pequeno burguês vienense, e que o inconsciente, na real, poderia passar sem ele. O segundo, o de que o analista é um intruso, um ruído estranho no gozo autoerótico de um sujeito que não comporta alteridade.

Por mais estranho que possa parecer, não me foi possível descartar nenhum dos dois sentidos ao ler os últimos cursos de Miller - e se minha afirmação parecer muito absurda, sugiro que se reportem a eles para ver se a endossam ou a rejeitam -, no que os dois contradizem proposições lacanianas muito claras, a saber, que o analista faz parte do conceito de inconsciente (Lacan, 1960-1964), e que a alteridade e as relações de objeto estão dadas de saída (1956-1957, 1957-1958, 1964, dentre inúmeras outras), bem como a referência freudolacaniana de que o analista atua, justamente, por se oferecer como objeto real da pulsão, participando daquilo que Lacan (1964) chama de realidade do inconsciente (que é o próprio circuito pulsional) e do que Freud define como a dinâmica da transferência (1912).

É claro que se poderia objetar que estas proposições de Lacan não são contemporâneas ao terceiro ensino, no que, talvez, seja possível que o próprio Lacan tenha mudado radicalmente seus paradigmas e proposições à altura do final de seu ensino. Pois bem, justamente, não é o que me pareceu ao ler os seminários finais de Lacan e, nem mesmo, aquele que Miller aponta como seu paradigma, o Seminário 23.

Nele Lacan formula que "o verdadeiro real implica a ausência de lei", que "o real é sem lei" (Lacan, 1975-1976, p. 133), em clara referência à insuficiência da lógica do significante como aquilo que poderia legislar sobre o real, conferir-Ihe sentido. Entretanto, ele também afirma que é em consequência disso que se poderá chegar a articular um pedaço de real, que é apenas ao esbarrar com a ausência de lei, de sentido, que se estará às portas do real:

Há uma orientação, mas essa orientação não é um sentido. O que quer dizer isso? Retomo o que disse da última vez sugerindo que o sentido seja, talvez, a orientação. 
Mas a orientação não é um sentido, uma vez que ela exclui o único fato da copulação do simbólico e do imaginário em que consiste o sentido. A orientação do real, no território que me concerne, foraclui o sentido. (Lacan, 1975-1976, p. 117)

A orientação para o real em Lacan - creio que tenha mostrado nesta passagem - é orientação do real. Isso significa que ali está o simbólico, inserindo uma orientação, fazendo furo no real. Sim, não há lei para o real, mas há orientação, ele é mordido, furado pelo simbólico, no que o funcionamento do significante continua sendo alguma coisa que se impõe a título de orientação.

O ponto é que Lacan não postula nenhum acesso ao real que não seja aquele do sinthoma, que é o osso do sintoma:

Eu reduzia o sinthoma, que está aqui, a alguma coisa que corresponde não à elucubração do inconsciente, mas à realidade do inconsciente. É certo que, mesmo sob essa forma, isso implica um terceiro termo, que mantenha separadas essas duas rodinhas de barbante.

Esse terceiro termo pode ser o que quisermos. Mas se o sinthoma é considerado equivalente do real, esse terceiro termo só pode ser, nessa circunstância, o imaginário. (Lacan, 1975-1976, pp. 134-135, grifos meus)

Lacan acrescenta: "sendo o real desprovido de sentido, não estou certo de que o sentido desse real não poderia se esclarecer ao ser tomado por nada menos que um sinthoma (Lacan, 1975-1976, p. 131).

O termo realidade do inconsciente volta a aparecer, ecoando as formulações do décimo primeiro seminário (Lacan, 1964), o que dá indícios de que não me equivoco tanto quando estranho a fórmula do analista como próton pseudos, pois ela parece contrariar formulações freudianas e lacanianas quanto à presença do analista na realidade do inconsciente. Ao situar as coisas desta maneira, portanto, significa dizer que as tentativas de cercear o real não são intrusas ou falaciosas. Quer dizer, sim, que as interpretações que visam o sentido do sintoma (a fórmula simbólica em causa numa construção imaginária, fantasmática) mostram-se sempre insuficientes para conferir sentido ao enigma sintomático, mas nada insuficientes em revelar sua realidade. 0 que resta impossível de analisar, a isso Lacan chama de sinthoma, é articulação entre simbólico e real, e não puro real perturbador e insuportável. Não há cura para o sinthoma, mas há suportabilidade no simbólico para ele, uma vez que ele pode ser nomeado.

Se nos reportarmos ao lugar, ao estatuto do analista, as coisas ficarão ainda mais claras: "Penso que não se pode conceber o psicanalista de outra forma se não como um sinthoma" (Lacan, 1975-1976, p. 131), sinthoma no sentido de articulação entre o real e o simbólico, de 
redução do sentido através de uma depuração do imaginário presente na estrutura. O que Lacan faz neste seminário, na minha leitura, é radicalizar a função simbólica disjunta do significado (imaginário), mas enodada com o real (sinthoma):

É de suturas e emendas que se trata na análise. Mas convém dizer que devemos considerar as instâncias como realmente separadas. Imaginário, simbólico e real não se confundem.

Encontrar um sentido implica saber qual é o nó, e emendá-lo bem graças a um artifício. (Lacan, 1975-1976, p. 71)

\section{Lacan acrescenta que:}

Quando fazemos essa emenda, fazemos ao mesmo tempo uma outra, precisamente entre o que é simbólico e o real. Isso quer dizer que, por algum lado, ensinamos o analisante a emendar, a fazer emenda entre seu sinthoma e o real parasita do gozo. O que é característico de nossa operação, tornar esse gozo possível. (Lacan, 19751976, pp. 70-71)

Desta maneira, ao interpretar o sentido (relação simbólico-imaginário), o analista conduz um outro enodamento: pela própria estrutura da interpretação, que é a de jogar com o sentido, as formações do inconsciente vão cedendo lugar a uma estrutura simbólica sem sentido, mas que não deixa de insistir ainda assim.

Essa insistência não se deve a outra coisa senão à relevância desse simbólico na viabilização de um certo gozo, na orientação do real sem sentido. Esta emenda entre o simbólico e o real é o analista-sinthoma que a realiza. Ela tem um estatuto traumático, visto que "o real em questão tem o valor do que chamamos geralmente de um trauma", entendendo por isso "não que eu visasse a traumatizar quem quer que fosse, (. . . ) é o forçamento de uma nova escrita" (Lacan, 1975-1976, p. 127). Ou seja, o estatuto e o lugar do analista são bastante sólidos e firmes no último ensino de Lacan, e não me lembram nenhum proton pseudos. Esta designação de ficção ficaria muito justa se fosse atribuída à cena transferencial, que é uma ficção de amor a respeito do trauma que um analista presentifica em uma análise.

\section{Analista como parceiro-sinthoma lá e aqui}

Para Coelho dos Santos (2014), o estatuto do analista no último ensino de Lacan está orientado pelo real da inexistência da relação sexual, ou seja, ao divorciar as construções simbólicas de suas cenas imaginárias e ainda sim dar-se conta de que há enodamento destas construções com o real do gozo, que elas o orientam, evidencia-se, através da ausência de 
sentido, que esse enodamento é contingente, tal qual o encontro de um homem com uma mulher. Da mesma forma estabelecer-se-ia qual lugar um analista ocupa para um ser falante na contingencialidade de um parceiro-sinthoma. É bem verdade, entretanto, que o termo parceirosinthoma é cunhado pelo próprio Miller (2008) para falar do estatuto do analista no último ensino. Então, por que o cito aqui para fazer oposição às elaborações do próprio Miller?

Porque, para Coelho dos Santos (2014), há uma diferença que entendo como crucial. Ao analisar as diferenças entre os relatos de passe da AMP nos anos de 1994 e 2010-2011 a autora nos mostra que houve uma mudança significativa. Os passes de 1994 foram bastante criteriosos com a produção de um saber, de cada analista, sobre seu próprio caso clínico: era preciso dizer sobre sua neurose infantil, elencar os pontos de efeito da análise sobre seu fantasma, sobre a cura de seus sintomas e os imperativos superegoicos. Esse é um passe na direção do escrito lacaniano (Lacan, 1967).

Quanto aos passes de 2010-2011, há uma mudança de concepção. Ainda segundo Coelho dos Santos (2014), há um predomínio do relato do que não foi curado pela análise, do relato dos restos incuráveis e de como o passante em questão conseguiu transformar isso em algo estilizado, em algo semelhante ao desejo de exibir-se, de ser ator. Isso não é nenhuma excentricidade, entretanto, pois que mostro com as palavras do próprio Miller (2014):

Faire une analyse, c'est travailler à la castration de l'escabeau pour mettre au jour la jouissance opaque du symptôme. Mais faire la passe, c'est jouer du symptôme ainsi nettoyé pour s'en faire un escabeau, aux applaudissements du groupe analytique. (...) les applaudissements ne sont pas du tout adventices". [§] "L'événement de passe, c'est le dire d'un seul, l'Analyste de l'École, quand il met en ordre son experiénce, quando il l'interprète au bénéfice du tout venant d'un congrès qu'il s'agit de séduire et d'enflammer. (Miller, 2014)

Ou seja, para Miller, o passe é uma situação onde um Analista da Escola relata sua experiência de modo a seduzir, inflamar e ser aplaudido por um certo grupo psicanalítico. A função de produção de saber universalizável - sobre a própria estrutura, de modo particular, e em benefício da ciência da clínica de modo amplo - é trocada por um modo em benefício da exaltação de grupos particulares de psicanalistas.

Ainda, portanto, que ambos os autores valham-se do termo "parceiro-sintoma" para falar do estatuto do analista no último ensino de Lacan, Coelho dos Santos (2014) o toma na acepção de contingencialidade no real que faz acontecer uma parceria que pode orientar o analisando na construção de um saber sobre seu modo particular de se haver com o real na inexistência da relação sexual, resultando em sua identificação ao sinthoma, ao seu tipo sexual - homem ou mulher - em sua diferença inelutável. 
Miller (2014), por sua vez, entende que sinthoma seja a sublimação de um modo singular de gozo, e da maneira que dá a entender, trata-se de fazer talk show ou stand up - quiçá um testemunho à la evangelismo - de como a psicanálise tornou-lhe gozável para si mesmo de maneira cool. Isso sim, para mim, soa como um pseudos.

\section{Da problemática ao problema de pesquisa: o estatuto do psicanalista é o do trauma ou o da ficção?}

Deste estranhamento crítico a certas construções de Miller, e da minha própria demanda clínica, fiz do lugar do analista um problema de pesquisa, uma vez que o vejo como crucial para a orientação da psicanálise na clínica do século XXI. Este problema pode ser traduzido pela pergunta: no último ensino de Lacan o estatuto do psicanalista é o do trauma, quer dizer, é real? ou é o da fiç̧ão? A metodologia que adoto para responder a este problema é o resgate dos lugares do analista ao longo do ensino de Lacan. $O$ interesse no estudo deste objeto pode ser justificado pelo ganho em duas vertentes, uma teórica e a outra clínica.

Do ponto de vista teórico, formular o lugar do analista ao longo do ensino de Lacan equivale a reconstruir toda a estrutura que ele confere à experiência analítica para, só então, designar seu lugar. No sentido tópico, um lugar não é meramente uma coordenada, mas uma posição ocupada em relação a outras posições onde uma assume uma função em relação a cada uma das outras (Lacan, 1957-1958). É só em relação a uma constelação de lugares, portanto, que o lugar do analista pode extrair, de uma estrutura, sua eficácia.

Eficácia é um termo chave para minha pesquisa, e nenhuma articulação que eu fizer sobre o lugar do analista estará isenta de remeter-se a ele, pois entendo que o que é eficaz é o que produz efeitos no real (ou que faça efeitos de real), efeitos estes que apenas as intervenções do analista corretamente posicionado podem provocar. Desta forma, orientar a leitura de Lacan pelo lugar do analista é uma maneira de orientar-se pelo que é clinicamente eficaz.

A hipótese, portanto, que atravessa toda minha pesquisa é de que o trabalho teórico que realizo poderá mostrar que o analista é alguma coisa mais do que uma mentirinha ou um inconveniente, que ele é tão real quanto o traumático, chegando mesmo a equivaler a ele.

Por sua vez, do ponto de vista clínico, penso, é crucial e urgente que o analista saiba onde é o seu lugar. Crucial porque é preciso saber se posicionar com o máximo de precisão que uma teoria rigorosa e consistente permite. Assim, espero que ao construir o lugar do analista como conceito, o faça de maneira operacional, que permita aos analistas saberem um pouco mais em que lugar estão se colocando, que tipo de implicações existem em se posicionar ali, e quais efeitos espera-se que as intervenções feitas a partir deste lugar possam provocar. A expectativa é que façam efeitos reais sobre o sofrimento e o modo de gozo dos analisados.

Aos interessados nesta linha de trabalho, peço que se reportem à primeira parte desta pesquisa, que resultou na minha dissertação de mestrado "Os lugares do analista no ensino de 
Lacan" (Silva Neto, 2013), onde acompanho o ensino de Lacan dos anos 1940 a 1964, ou seja, todo o seu primeiro ensino e o início do segundo, com o objetivo de precisar teoricamente o lugar e o estatuto do analista a cada momento, bem como o de mostrar que alterações na teoria resultam em mudanças nas concepções deste lugar.

Quanto à restante da série histórica do ensino de Lacan, de 1965 a 1980, espero retomar os trabalhos em minha tese de doutorado.

Nota:

${ }^{1}$ Este trabalho é resultado de minha dissertação de mestrado, "Os lugares do analista no ensino de Lacan" (Silva Neto, 2013), orientada pela Prof. Dra. Tania Coelho dos Santos. Curso de Pósgraduação em Teoria Psicanalítica, Instituto de Psicologia, Universidade Federal do Rio de Janeiro.

\section{Referências Bibliográficas}

Coelho dos Santos, T. (2014). Do supereu sujeitado à lei simbólica à normatividade supersocial dos corpos falantes. In Coelho dos Santos, T. et al. (Orgs.) Os corpos falantes e a normatividade do supersocial (pp. 27-63). Rio de Janeiro: Cia de Freud.

Freud, S. (1996). Cinco lições de psicanálise. In J. Salomão (Trad.) Edição standard brasileira das obras psicológicas completas de Sigmund Freud (Vol. 11, pp. 143-156). Rio de Janeiro: Imago (Trabalho original publicado em 1910).

Freud, S. (1996). Notas Psicanalíticas sobre um relato autobiográfico de um caso de paranóia (Dementia Paranoides). In J. Salomão (Trad.) Edição standard brasileira das obras psicológicas completas de Sigmund Freud (Vol. 12, pp. 15-89). Rio de Janeiro: Imago (Trabalho original publicado em 1911).

Freud, S. (1996). A dinâmica da transferência. In J. Salomão (Trad.) Edição standard brasileira das obras psicológicas completas de Sigmund Freud (Vol. 12, pp. 109-119). Rio de Janeiro: Imago (Trabalho original publicado em 1912).

Freud, S. (2007). O Eu e o Id. In L. A. Hans (Trad.) Escritos sobre a psicologia do inconsciente (Vol. 3, pp. 13-71). Rio de Janeiro: Imago (Trabalho original publicado em 1923).

Freud, S. (1996). Neurose e psicose. In J. Salomão (Trad.) Edição standard brasileira das obras psicológicas completas de Sigmund Freud (Vol. 19, pp. 167-171). Rio de Janeiro: Imago (Trabalho original publicado em 1924a).

Freud, S. (1996). A perda da realidade na neurose e na psicose. In J. Salomão (Trad.) Edição standard brasileira das obras psicológicas completas de Sigmund Freud (Vol. 19, pp. 205209). Rio de Janeiro: Imago (Trabalho original publicado em 1924b).

Freud, S. (1996). Análise terminável e interminável. In J. Salomão (Trad.) Edição standard brasileira das obras psicológicas completas de Sigmund Freud (Vol. 23, pp. 225-270). Rio de Janeiro: Imago (Trabalho original publicado em 1937). 
Freud, S. (1996). Esboço de psicanálise. In J. Salomão (Trad.) Edição standard brasileira das obras psicológicas completas de Sigmund Freud (Vol. 23, pp. 153-221). Rio de Janeiro: Imago (Trabalho original publicado em 1940).

Lacan, J. (1998). Função e campo da fala e da linguagem em psicanálise. In V. Ribeiro (Trad.) Escritos (pp. 238-324). Rio de Janeiro: Jorge Zahar (Trabalho original publicado em 1953).

Lacan, J. (2008). O seminário, livro 3: as psicoses. Rio de Janeiro: Zahar (Trabalho original publicado em 1955-1956).

Lacan, J. (1998). A instância da letra no inconsciente, ou a razão desde Freud. In V. Ribeiro (Trad.) Escritos (pp. 496-533). Rio de Janeiro: Jorge Zahar (Trabalho original publicado em 1957).

Lacan, J. (1999). O seminário, livro 5: as formações do inconsciente. Rio de Janeiro: Jorge Zahar (Trabalho original publicado em 1957-1958).

Lacan, J. (1998). A significação do falo. In V. Ribeiro (Trad.) Escritos (pp. 692-703). Rio de Janeiro: Jorge Zahar (Trabalho original publicado em 1958).

Lacan, J. (1998). Posição do inconsciente. In V. Ribeiro (Trad.) Escritos (pp. 843-864). Rio de Janeiro: Jorge Zahar (Trabalho original publicado em 1960-1964).

Lacan, J. (2010). O seminário, livro 8: a transferência. Rio de Janeiro: Jorge Zahar (Trabalho original publicado em 1960-1961).

Lacan, J. (2005). O seminário, livro 10: a angústia. Rio de Janeiro: Jorge Zahar (Trabalho original publicado em 1962-1963).

Lacan, J. (2008). O seminário. Livro 11: Os quatro conceitos fundamentais da psicanálise. Rio de Janeiro: Zahar (Trabalho original publicado em 1964).

Lacan, J. (2003). Proposição de 9 de outubro de 1967 sobre o psicanalista da Escola. In V. Ribeiro (Trad.) Outros Escritos (pp. 248-264). Rio de Janeiro: Jorge Zahar (Trabalho original publicado em 1967).

Lacan, J. (1992). O seminário, livro 17: o avesso da psicanálise. Rio de Janeiro: Zahar (Trabalho original publicado em 1969-1970).

Lacan, J. (2009). O seminário, livro 18: de um discurso que não fosse semblante. Rio de Janeiro: Jorge Zahar (Trabalho original publicado em 1971).

Lacan, J. (2012). O seminário, livro 19: ...ou pior. Rio de Janeiro: Jorge Zahar (Trabalho original publicado em 1971-1972).

Lacan, J. (2008). O seminário, livro 20: mais, ainda. Rio de Janeiro: Jorge Zahar (Trabalho original publicado em 1972-1973).

Lacan, J. (2003). Televisão. In V. Ribeiro (Trad.) Outros Escritos (pp. 508-543). Rio de Janeiro: Jorge Zahar (Trabalho original publicado em 1973).

Lacan, J. (1973-1974). O seminário, livro 21: RSI. Seminário inédito.

Lacan, J. (2007). O seminário, livro 23: o sinthoma. Rio de Janeiro: Jorge Zahar (Trabalho original publicado em 1975-1976). 
Lacan, J. (2003). Joyce, o sinthoma. In V. Ribeiro (Trad.) Outros Escritos (pp. 560-566). Rio de Janeiro: Jorge Zahar (Trabalho original publicado em 1975).

Miller, J.-A., Laurent, E. et al. (1998). Os casos raros, inclassificáveis, da clínica psicanalítica: a conversação de Arcachon. São Paulo: Biblioteca Freudiana Brasileira.

Miller, J.-A. (2007). Orientação lacaniana III, 9 - O inconsciente Real. Rio de Janeiro: Escola Brasileira de Psicanálise.

Miller, J.-A. (2008). El partenaire-síntoma. Buenos Aires: Paidós.

Miller, J.-A. (2009). Perspectivas do seminário 23 de Lacan: o sinthoma. Rio de Janeiro: Jorge Zahar.

Miller, J.-A. (2010). Orientação lacaniana III, 11 - Coisas de fineza em psicanálise. Rio de Janeiro: Escola Brasileira de Psicanálise.

Miller, J.-A. (2011). Perspectivas dos Escritos e Outros escritos e Lacan: Entre desejo e gozo. Rio de Janeiro: Jorge Zahar.

Miller, J.-A. (abr. 2014). L'inconscient et le corps parlant. Association Mondiale de Psychanalyse.

Recuperado

de

http://wapol.org/fr/articulos/Template.asp?intTipoPagina=4\&intPublicacion=13\&intEdicion=9\& intIdiomaPublicacion $=5$ \&intArticulo $=2742$ \&intIdiomaArticulo $=5$.

Silva Neto, E. A. (2011). O desejo pelo parceiro-máquina. In Revista aSEPHallus, 6(11), 228-231. Recuperado de http://www.isepol.com/asephallus/numero_11/resenha_02_revista11.html.

Silva Neto, E. A. (2013). Os lugares do analista no ensino de Lacan. (Dissertação de mestrado). Universidade Federal do Rio de Janeiro, Rio de Janeiro.

Soler, C. (2012). Lacan, o inconsciente reinventado. Rio de Janeiro: Cia. de Freud.

CITACÃo/CITATION: Silva Neto, E. A. (mai. a out. 2014). Orientação do real. Revista aSEPHallus de Orientação Lacaniana, 9(18), 36-49. Disponível em www.isepol.com/asephallus. doi: 10.17852/1809709x.2019v9n18p36-49.

Editor do artigo: Tania Coelho dos Santos.

Recebido/Received: 28/08/2013 / 08/28/2013.

Aceito/Accepted: 13/10/2013 / 10/13/2013.

Copyright: (C) 2013 Associação Núcleo Sephora de Pesquisa sobre o moderno e o contemporâneo. Este é um artigo de livre acesso, que permite uso irrestrito, distribuição e reprodução em qualquer meio, desde que o autor e a fonte sejam citados/This is an open-access article, which permites unrestricted use, distribution, and reproduction in any medium, provided the author and source are credited. 